\title{
Willingness for deceased organ donation under different legislative systems in Hong Kong: population-based cross-sectional survey
}

\author{
TK Cheung, TC Cheng, LY Wong *
}

\begin{abstract}
A B S T R A C T
Introduction: Under the current opt-in system, the deceased organ donation rate remains low in Hong Kong. An opt-out system and an opt-in system combined with organ allocation priority (ie, priority to donors as transplant recipients) have been proposed to encourage willingness among the general population towards deceased organ donation. This study aimed to compare willingness, and its determinants, across these three legislative systems.
\end{abstract}

Methods: A random telephone survey of Hong Kong permanent residents aged $\geq 18$ years was conducted between August and October 2016 using an anonymous questionnaire. Willingness towards deceased organ donation was compared between the legislative systems with McNemar's test. Determinants of willingness were tested by logistic regression.

Results: The proportion of those willing to consider deceased organ donation under the current opt-in system would significantly increase after combining it with allocation priority $(64.5 \%$ vs $73.4 \%$; $\mathrm{P}=0.018)$.

This article was published on $10 \mathrm{Apr}$ 2018 at www.hkmj.org.
"Fairness or reciprocity" was the major reported reason underlying the increase. In contrast, willingness would decrease after introducing the opt-out system (60.1\%), although not significantly $(\mathrm{P}=0.336)$. The reduction might be attributable to a "belief of being forced to donate". Under the allocation priority system, reduced willingness to donate was associated with advanced age, lower educational attainment, and lower monthly household income. Under the opt-out system, reduced willingness was associated with being married, having a lower household income, and distrust of local government.

Conclusions: An opt-in system with allocation priority could induce willingness to donate, whereas an opt-out system may reduce willingness. The findings have implications for policy-making and promotion of organ donation.

\section{Hong Kong Med J 2018;24:119-27 \\ DOI: 10.12809/hkmj176831}

TK Cheung, BSc

TC Cheng, BSC

LY Wong *, BSN, MPH, PhD

The Jockey Club School of Public Health and Primary Care, The Chinese University of Hong Kong, Prince of Wales Hospital, Shatin, Hong Kong

* Corresponding author: lywong@cuhk.edu.hk

New knowledge added by this study

- Introducing organ allocation priority to the current opt-in system is expected to significantly increase willingness of the Hong Kong general population for deceased organ donation.

- Replacing the opt-in system by an opt-out system may cause a reduction in willingness to donate. A portion of registered donors (15.8\%) and of the general population who were willing to donate organs under the current opt-in system (28.2\%) said they were reluctant to stay in the donor pool under the proposed opt-out system.

Implications for clinical practice or policy

- The present study can help health care policymakers anticipate public attitude towards implementing an opt-out system and its potential effectiveness.

- The findings support alternative legislative systems of deceased organ donation other than the opt-out system, such as an opt-in allocation priority system.

- Apart from modification of the legislative system for organ donation, the government should consider policies designed to motivate registering behaviour.

\section{Introduction}

Organ transplantation offers the best clinical management for patients with end-stage organ failure. Since the first successful kidney transplant in $1954,{ }^{1}$ a number of studies have confirmed that organ transplantation provides the best outcomes for survival, ${ }^{2}$ quality of life, ${ }^{3}$ and cost-effectiveness. ${ }^{4}$
With advances in surgical techniques and immunosuppressive drugs, organ donation has also progressively improved over the decades. However, the low rate of deceased organ donation is a universal problem. Different countries have adopted different policy schemes to encourage deceased organ donation but the donation rates vary. 


\section{在不同立法機制下的死後器官捐贈意願： 普及人口的橫向研究 \\ 張梓敬、鄭芷澄、黃麗儀}

引言：在現時的「自願捐贈機制」下，香港的遺體器官捐贈率偏低。 $「$ 預設默許機制」及「分配優先機制」（即自願捐贈者將來在移植名 單上享有優先權）被擬議，以增加香港市民對死後器官捐贈的意願。 本研究旨在比較這三種立法機制下的捐贈意願, 並探討擬議制度下捐 贈意願的決定因素。

方法：在 2016 年 8 月至 10 月期間，使用匿名問卷對 18 歲或以上的香港 永久性居民進行隨機電話調查。在各種立法機制下的捐贈意願以麥內 瑪關聯樣本檢定進行比較, 而捐贈意願的決定因素則進行邏輯回歸測 試。

結果：加入「分配優先機制」後，現時 $「$ 自願捐贈機制」下的捐贈 意願比率將顯著增加（由64.5\%升至 $73.4 \%, P=0.018$ ）。「公平或 互惠」可能是增加的主要原因。相反, 在「預設默許機制」下, 雖 然在統計上不算顯著（ $\mathrm{P}=0.336 ）$, 但捐贈意願的比率則有所下降 $(60.1 \%)$ 。此下降歸因於「被迫捐贈的觀念」。在「分配優先機 制」下, 捐贈意願較低與年齡較大、教育程度較低及家庭每月收入較 低相關。在「預設默許機制」下, 捐贈意願較低則與已婚、家庭每月 收入較低以及不信任地方政府相關。

結論：加入「分配優先機制」的「自願捐贈機制」能增加捐贈意願， 反之「預設默許機制」則削弱捐贈意願。本研究結果提供對政策制定 和宣傳的啓示。 from several European countries, implementing an opt-out system can successfully raise awareness and willingness for deceased organ donation ${ }^{12}$ and actual donation rates. ${ }^{11,13-15}$

An opt-in system with allocation priority is another policy approach, in which individuals who have registered as a deceased donor will gain priority points on the transplant waiting list. A priority point is a reward for those who are willing to donate an organ and who in turn gain preferential status for receiving a donor organ if required. ${ }^{16}$ This system can motivate the public to register as donors by providing them with a higher chance of extending their own lives and address the perceived unfairness of 'free-riders' who are willing to receive an organ but unwilling to donate. Israel adopted this policy approach in the Organ Transplant Act of 2008 and illustrated its effectiveness by the number of signed donor cards and actual donation rates. ${ }^{10,16,17}$

In light of the low deceased organ donation rate in Hong Kong, the government is currently reviewing its donation policy and is considering replacing the current opt-in system by an opt-out system. However, introducing an opt-out system without public support may actually reduce the donation rate, ${ }^{18}$ as it did in Brazil and Singapore. ${ }^{6}$ Similarly, ethical issues of the allocation priority system may fuel public opposition. On the one hand, it promotes a fair concept of reciprocity. ${ }^{16,19}$ On the other hand, there is a perception that organ allocation should be based not on an individual's willingness to donate, but solely on their medical needs. ${ }^{16,19}$ It is difficult to predict the effectiveness of proposed legislative systems in Hong Kong on the basis of experience elsewhere, and local analysis of these systems is limited. Only one local study has examined the willingness to donate a kidney under an opt-out system but the feasibility of allocation priority was not included. ${ }^{20}$ In addition, socio-economic and demographic determinants may influence willingness towards deceased organ donation. A Malaysian study suggested that such determinants may differ under different legislative systems. ${ }^{21}$ Interestingly, political viewpoint is also correlated with willingness when a new legislative system is imposed. ${ }^{12,22}$ It is thus important to explore these determinants when considering an opt-out system or allocation priority system. country to advance their organ procur programme. $^{9}$ Two legislative systems have been proposed to increase the donation rate: an opt-out system and an opt-in system with organ allocation priority (allocation priority system). ${ }^{10}$ An opt-out system presumes an individual is a potential deceased donor unless refusal has been expressed by 'opting out' of the donor pool. This system can simplify registration procedures and is convenient for those willing to donate organs. An opt-out system, however, does not specifically indicate willingness. ${ }^{11}$ On the basis of empirical evidence

\section{Study aims}

This study aimed to explore whether a proposed opt-out system or opt-in allocation priority system would increase public willingness in Hong Kong towards deceased organ donation, and to examine the association of socio-economic, demographic, and political determinants with the willingness of deceased organ donation under different proposed policies. 


\section{Methods}

A cross-sectional telephone survey with a structured questionnaire was conducted. The target population was Hong Kong permanent residents who were aged $\geq 18$ years, able to register as a deceased organ donor, and able to speak Cantonese. On the basis of the ' $10 \mathrm{k}$ rule of thumb, ${ }^{23}$ the minimum sample size required to test the association between the willingness of organ donation and the seven socio-demographic variables in this study was about 200. Assuming a 0.05 type 1 error, the sample size would be able to detect $15 \%$ and $20 \%$ significant differences in the proportions of persons shifting from 'unwilling' to 'willing' to donate after proposing the allocation priority system and opt-out system, respectively, both with at least $80 \%$ power. With the assumption that $12 \%$ of landline telephone numbers are valid and there would be a $30 \%$ response rate, a sample of about 5600 telephone numbers was needed. A computerised random list of 5800 eight-digit residential telephone numbers (starting with ' 2 ' and ' 3 ', the current telephone number system in Hong Kong) was generated.

Telephone interviews were held from 18:00 to $20: 30$ on every weekday and from $11: 00$ to $18: 00$ on every weekend to ensure coverage of different demographics. The actual proportions of calls made on weekdays and at weekends were $41.3 \%$ and $58.7 \%$, respectively. Interviews were conducted by the first two authors and each took about 5 to 7 minutes, including an introduction explaining the interview and obtaining verbal consent. A maximum of three calls was made at different times on different days before a telephone number was considered invalid. If more than one family member in a household was eligible, the person whose next birthday was closest to the interview date was invited to participate.

The questionnaire was developed from a literature review and comprised 14 items in four sections: (1) current opt-in system; (2) proposed opt-out system; (3) proposed opt-in allocation priority system; (4) background information: socioeconomic and demographic characteristics and political views. Reasons underlying the willingness under each legislative system were explored with open-ended questions. On the basis of a pilot study of the questionnaire's feasibility and wording, involving 10 members of the general public, descriptions of the two proposed systems were refined. Double-entry of data and data cleaning were conducted by the authors. Ethics approval was granted by the Survey and Behavioural Research Ethics Committee of The Chinese University of Hong Kong.

All statistical analyses were performed with IBM SPSS Statistics 24 (IBM Corp, Armonk [NY], USA). A descriptive summary of characteristics of respondents compared with those of the targeted general population ${ }^{24}$ was prepared. Two-sided
McNemar's tests were used to compare willingness rates between the current opt-in system and the opt-out system, as well as between the current opt-in system and the allocation priority system. Univariate logistic regression analyses were performed to explore associations between each independent variable (demographics, socio-economic level, and political view) and the dependent variable (willingness of deceased organ donation) under the proposed opt-out and allocation priority systems, separately. Significant independent variables were further tested by multiple logistic regression analysis using the forced entry method. $\mathrm{P}<0.05$ was considered statistically significant. A qualitative content analysis was also conducted by the first author to identify meaningful units emerging from the open-ended questions for underlying reasons for willingness to donate. The units were coded into categories based on the findings and suggested by the literature review, $6,16,17,25$ and were checked independently by the second author.

\section{Results}

\section{Telephone interview response rate}

Telephone interviews took place between 2 August and 18 October 2016 in Hong Kong. A total of 5800 households were contacted and 203 respondents completed the questionnaire (response rate, 19.7\%) (Fig).

\section{Characteristics of respondents}

The majority of the respondents were female $(60.9 \%$ of 202), were aged 18 to 30 years (43.2\% of 199), had a post-secondary education (41.0\% of 200$)$, were employed (54.0\% of 202), were never married (52.3\% of 197), and had a monthly household income of more than HK\$40000 (37.6\% of 189). Compared with

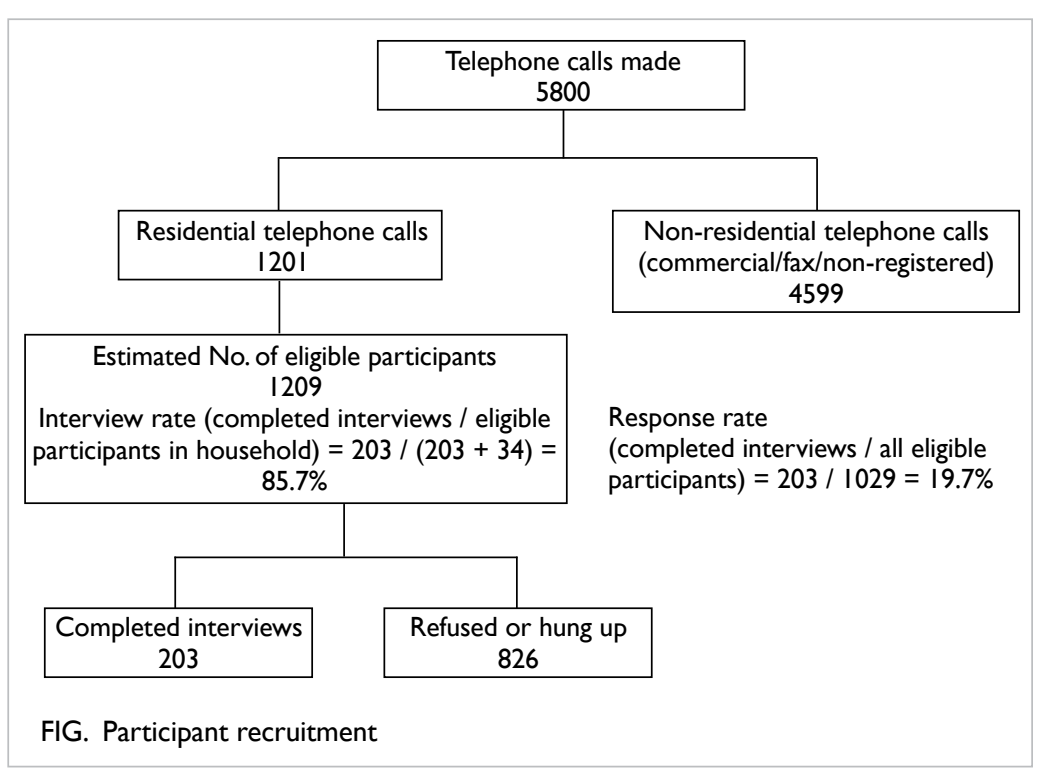


the general population, our study sample contained smaller proportions who were male, older than 40 years, educated to secondary level, or married, or who had a household income of $<\mathrm{HK} \$ 20000$. (Table $1)$.

\section{Willingness towards deceased organ donation}

Under the current opt-in system, a majority of respondents were willing to donate organs after death (64.5\%), whereas some were unwilling (11.8\%) and others were unsure (23.6\%) [Table 2]. Among those willing to donate, only $29.0 \%$ had registered as deceased donors.

After the opt-out system was proposed, 37.0\% of respondents who were unsure about donation or had been unwilling to donate previously, reported

TABLE I. Socio-economic and demographic characteristics of respondents and the general population

\begin{tabular}{|c|c|c|}
\hline Characteristic (No. of respondents) ${ }^{*}$ & $\begin{array}{l}\text { Respondents, } \\
\text { No. (\%) }\end{array}$ & $\begin{array}{c}\text { General population, } \\
\text { No. }(\%) \\
{[n=5961898]}\end{array}$ \\
\hline \multicolumn{3}{|l|}{$\operatorname{Sex}(n=202)$} \\
\hline Male & $79(39.1)$ & $2672876(44.8)$ \\
\hline Female & $123(60.9)$ & $3290033(55.2)$ \\
\hline \multicolumn{3}{|l|}{ Age, y $(n=199)$} \\
\hline $18-30$ & $86(43.2)$ & $929086(15.6)$ \\
\hline $31-40$ & $38(19.1)$ & $1134463(19.0)$ \\
\hline $41-50$ & $26(13.1)$ & $1117056(18.7)$ \\
\hline $51-60$ & $25(12.5)$ & $1234916(20.7)$ \\
\hline$>60$ & $24(12.1)$ & $1546377(25.9)$ \\
\hline \multicolumn{3}{|l|}{ Education level $(n=200)$} \\
\hline No schooling or primary & $53(26.5)$ & $1534539(25.7)$ \\
\hline Lower/upper secondary & $65(32.5)$ & 2528727 (42.4) \\
\hline Post-secondary & $82(41.0)$ & $1898632(31.8)$ \\
\hline \multicolumn{3}{|l|}{ Occupation (n=202) } \\
\hline Employee/employer/self-employed & $109(54.0)$ & $3398925(57.0)$ \\
\hline Family-maker/retired & $49(24.2)$ & $1564856(26.2)$ \\
\hline Student & $44(21.8)$ & $998118(16.7)$ \\
\hline \multicolumn{3}{|l|}{ Marital status $(n=197)$} \\
\hline Never-married & $103(52.3)$ & $1553148(26.1)$ \\
\hline Married & $73(37.0)$ & $3699750(62.1)$ \\
\hline Widowed & $12(6.1)$ & $384517(6.4)$ \\
\hline Divorced/separated & $9(4.6)$ & $324483(5.4)$ \\
\hline \multicolumn{3}{|l|}{ Monthly household income, HK\$ $(n=189) \dagger$} \\
\hline$<20000$ & $50(26.4)$ & $1027901(41.0)$ \\
\hline $20000-39999$ & $68(36.0)$ & $699450(27.9)$ \\
\hline$\geq 40000$ & $71(37.6)$ & 782383 (31.2) \\
\hline
\end{tabular}

* Did not total 203 because of missing data

+ Total No. of domestic households was 2509734 a willingness to stay in the donor pool. However, $15.8 \%$ of registered donors and $28.2 \%$ of respondents who had originally expressed a willingness to donate were reluctant to stay in the donor pool. Overall, the willingness rate decreased from $64.5 \%$ under the current opt-in system to $60.1 \%$ under the proposed opt-out system, although the reduction was not statistically significant. In contrast, combining the opt-in system with allocation priority motivated $64.8 \%$ of respondents originally unwilling to donate to instead express a willingness. Only $11.4 \%$ of those originally willing to donate were demotivated. This resulted in a statistically significant increase in the overall willingness rate, from $64.5 \%$ under the current opt-in system to $73.4 \%$ under the proposed allocation priority system $(\mathrm{P}=0.018)$ [Table 2].

Under the allocation priority system, respondents who changed their stance from unwilling to willing to donate $(n=35)$ did so largely because they perceived the system as a "fair or reciprocal" method of organ allocation (57.1\%). They believed they "had a greater chance of receiving an organ transplant if registered" (54.3\%). At the same time, some respondents who had originally expressed a willingness to donate were reluctant to do so under the priority system $(\mathrm{n}=17)$. They felt that the preferential status was useless, as "the waiting list would be still very long" (52.9\%). Some also mentioned that it was "unethical" if criteria other than medical condition were used for organ allocation (47.1\%) [Table 3].

After the opt-out system was explained, those who had been unsure about donor registration or unwilling to donate under the opt-in system $(n=30)$ were willing to stay in the donor pool because the opt-out system offered them "convenience for indicating willingness" (23.3\%). Moreover, some believed that remaining in the donor pool was a "civic duty" (20.0\%). Conversely, many respondents who had been willing to donate under the opt-in system chose to opt out $(n=39)$, as they perceived that under the system they were "forced to donate" (69.2\%). "Distrust of local government" was another reason $(30.8 \%)$ [Table 4 ].

\section{Determinants of willingness for deceased organ donation}

Associations between variables and willingness were first tested by univariate logistic regression for each legislative system (Table 5). Under the opt-out system, age, educational attainment, monthly household income, marital status, and political view were significantly associated with willingness. Under the allocation priority system, age, educational attainment, monthly household income, and marital status were the significant predictors. Sex and occupation were not significantly associated with a willingness to donate under either system. 
TABLE 2. Willingness towards deceased organ donation under current opt-in system and proposed opt-out and allocation priority systems $(n=203)$

\begin{tabular}{|c|c|c|c|c|c|}
\hline \multirow[t]{2}{*}{ Willingness } & \multirow{2}{*}{$\begin{array}{c}\text { Opt-in } \\
\text { No. (\%) }\end{array}$} & \multicolumn{2}{|c|}{ Opt-out } & \multicolumn{2}{|c|}{ Allocation priority } \\
\hline & & No. (\%) & P value* & No. (\%) & P value* \\
\hline Willing to donate & $131(64.5)$ & $122(60.1)$ & 0.336 & $149(73.4)$ & 0.018 \\
\hline Not willing to donate & $72(35.5)$ & $81(39.9)$ & - & $54(26.6)$ & - \\
\hline Unwilling to donate & $24(11.8)$ & $42(20.7)$ & - & $19(9.4)$ & - \\
\hline Unsure about donation & $48(23.6)$ & $39(19.2)$ & - & $35(17.2)$ & - \\
\hline
\end{tabular}

* Comparison with opt-in system

TABLE 3. Reasons for changing willingness towards deceased organ donation under proposed allocation priority system

\begin{tabular}{|c|c|}
\hline Reason & No. (\%) \\
\hline \multicolumn{2}{|l|}{ Reason for willingness to donate $(n=35)$} \\
\hline Greater chance of receiving an organ transplant & $20(57.1)$ \\
\hline Perception of fairness / reciprocity & 19 (54.3) \\
\hline Fear of being deprived transplant chances & $12(34.3)$ \\
\hline Others & $1(2.9)$ \\
\hline \multicolumn{2}{|l|}{ Reason for unwillingness to donate / unsure about donation $(n=17)$} \\
\hline Perception that the waiting list would still be very long & $9(52.9)$ \\
\hline Unethical if criterion other than medical condition was used for organ allocation & $8(47.1)$ \\
\hline Chance of needing organ transplant was small & $5(29.4)$ \\
\hline Distrust government & $4(23.5)$ \\
\hline Others & $2(11.8)$ \\
\hline
\end{tabular}

TABLE 4. Reasons for changing willingness towards deceased organ donation under proposed opt-out system

\begin{tabular}{ll}
\hline Reason & No. (\%) \\
\hline Reason for willingness to donate $(\mathrm{n}=30)$ & $7(23.3)$ \\
\hline Convenience for indicating willingness & $6(20.0)$ \\
\hline Treat 'remaining in donor pool' as civic duty & $5(16.7)$ \\
\hline Follow social norm & $3(10.0)$ \\
\hline Others & 27 (69.2) \\
Reason for unwillingness to donate / unsure about donation $(\mathrm{n}=39)$ & $13(33.3)$ \\
\hline Belief of being forced to donate & $12(30.8)$ \\
\hline Perceived violation of personal right & $10(25.6)$ \\
\hline Distrust of local government & $2(5.1)$ \\
\hline Fear about difficulty of changing idea / opting out & \\
\hline Others
\end{tabular}

These significant predictors were further donate, whereas those who trusted local government analysed by multiple logistic regression. Under an had a higher willingness (AOR=2.590, 95\% CI=1.023opt-out system, respondents who were married 6.554). Under an allocation priority system, lower (adjusted odds ratio $[\mathrm{AOR}]=0.423,95 \%$ confidence willingness to donate was associated with age over interval $[\mathrm{CI}]=0.205-0.871)$ or earned a monthly 60 years $(A O R=0.168,95 \% \mathrm{CI}=0.029-0.960)$, primary household income of $\angle \mathrm{HK} \$ 20000(\mathrm{AOR}=0.366,95 \%$ education level or no schooling (AOR=0.253, 95\% $\mathrm{CI}=0.162-0.827)$ or $\mathrm{HK} \$ 20000-39999(\mathrm{AOR}=0.447, \mathrm{CI}=0.077-0.829)$, and monthly household income of $95 \% \mathrm{CI}=0.207-0.962)$ had a lower willingness to $<\mathrm{HK} \$ 20000(\mathrm{AOR}=0.230,95 \% \mathrm{CI}=0.080-0.622)$. 
TABLE 5. Associations of respondent characteristics and political view with willingness towards deceased organ donation, by proposed system

\begin{tabular}{|c|c|c|c|c|c|c|}
\hline \multirow[t]{2}{*}{ Characteristic } & \multicolumn{3}{|c|}{ Opt-out system } & \multicolumn{3}{|c|}{ Allocation priority system } \\
\hline & No. $(\%)^{\star}$ & OR $(95 \% \mathrm{Cl})$ & AOR (95\% Cl) & No. $(\%)^{*}$ & OR (95\% Cl) & AOR (95\% Cl) \\
\hline \multicolumn{7}{|l|}{ Sext } \\
\hline Male & $45(57.0)$ & $0.791(0.444-1.407)$ & - & $54(68.4)$ & $0.637(0.338-1.201)$ & - \\
\hline Female & $77(62.6)$ & 1 (Ref) & - & 95 (77.2) & 1 (Ref) & - \\
\hline \multicolumn{7}{|l|}{ Age, y } \\
\hline$>60$ & $11(45.8)$ & $0.501(0.201-1.251)$ & $0.512(0.117-2.246)$ & $9(37.5)$ & $0.137(0.051-0.369) \ddagger$ & $0.168(0.029-0.960) \S$ \\
\hline $51-60$ & $16(64.0)$ & $1.053(0.417-2.660)$ & $1.206(0.389-3.744)$ & $17(68.0)$ & $0.486(0.179-1.321)$ & $0.622(0.171-2.261)$ \\
\hline $41-50$ & $10(38.5)$ & $0.370(0.150-0.914) \S$ & $0.579(0.182-1.842)$ & $17(65.4)$ & $0.432(0.163-1.143)$ & $0.317(0.080-1.251)$ \\
\hline $31-40$ & $30(78.9)$ & $2.222(0.909-5.434)$ & $2.871(0.996-8.272)$ & $35(92.1)$ & $2.667(0.728-9.767)$ & $2.504(0.508-12.351)$ \\
\hline $18-30$ & $54(62.8)$ & 1 (Ref) & 1 (Ref) & 70 (81.4) & 1 (Ref) & 1 (Ref) \\
\hline \multicolumn{7}{|l|}{ Education level } \\
\hline No schooling or primary & $26(49.1)$ & $0.473(0.233-0.960) \S$ & $0.755(0.273-2.089)$ & $26(49.1)$ & $0.181(0.081-0.404) \ddagger$ & $0.253(0.077-0.829) \S$ \\
\hline Lower/upper secondary & $40(61.5)$ & $0.785(0.398-1.550)$ & $0.915(0.416-2.011)$ & $53(81.5)$ & $0.832(0.351-1.971)$ & $1.244(0.453-3.410)$ \\
\hline Post-secondary & $55(67.1)$ & 1 (Ref) & 1 (Ref) & $69(84.1)$ & 1 (Ref) & 1 (Ref) \\
\hline \multicolumn{7}{|l|}{ Occupation $†$} \\
\hline Family-maker/retired & $27(55.1)$ & $0.740(0.374-1.466)$ & - & $31(63.3)$ & $0.567(0.274-1.172)$ & - \\
\hline Student & $27(61.4)$ & $0.958(0.466-1.967)$ & - & $36(81.8)$ & $1.482(0.614-3.576)$ & - \\
\hline $\begin{array}{l}\text { Employee/employer/self- } \\
\text { employed }\end{array}$ & $68(62.4)$ & 1 (Ref) & - & $82(75.2)$ & 1 (Ref) & - \\
\hline \multicolumn{7}{|l|}{ Marital status } \\
\hline Married & $35(47.9)$ & $0.454(0.246-0.837) \S$ & $0.423(0.205-0.871) \S$ & $47(64.4)$ & $0.447(0.227-0.878) \S$ & $1.201(0.389-3.713)$ \\
\hline Widowed & $9(75.0)$ & $1.479(0.377-5.808)$ & $1.281(0.261-6.287)$ & $9(75.0)$ & $0.741(0.184-2.979)$ & $3.705(0.390-35.236)$ \\
\hline Divorced/separated & $5(55.6)$ & $0.616(0.156-2.439)$ & $0.580(0.135-2.502)$ & $6(66.7)$ & $0.494(0.114-2.140)$ & $0.841(0.131-5.414)$ \\
\hline Never-married & $70(68.0)$ & 1 (Ref) & 1 (Ref) & 85 (82.5) & 1 (Ref) & 1 (Ref) \\
\hline \multicolumn{7}{|l|}{ Monthly household income, HK\$ } \\
\hline$<20000$ & $24(48.0)$ & $0.414(0.196-0.876) \S$ & $0.366(0.162-0.827) \S$ & $24(48.0)$ & $0.151(0.063-0.361) \ddagger$ & $0.230(0.080-0.622) \ddagger$ \\
\hline 20 000-39 999 & $39(57.4)$ & $0.604(0.301-1.211)$ & $0.447(0.207-0.962) \S$ & $54(79.4)$ & $0.632(0.260-1.540)$ & $0.395(0.138-1.126)$ \\
\hline$\geq 40000$ & $49(69.0)$ & 1 (Ref) & 1 (Ref) & $61(85.9)$ & 1 (Ref) & 1 (Ref) \\
\hline \multicolumn{7}{|l|}{ Political view $(n=201)$} \\
\hline Distrust government $(n=63)$ & $38(60.3)$ & $1.271(0.671-2.408)$ & $1.420(0.701-2.875)$ & $47(74.6)$ & $1.072(0.523-2.198)$ & - \\
\hline Trust government $(n=36)$ & $27(75.0)$ & $2.509(1.072-5.870) \S$ & $2.590(1.023-6.554) \S$ & $26(72.2)$ & $0.903(0.405-2.224)$ & - \\
\hline Neutral or no affiliation $(n=101)$ & $55(54.5)$ & 1 (Ref) & 1 (Ref) & $74(73.3)$ & 1 (Ref) & - \\
\hline
\end{tabular}

Abbreviations: $\mathrm{AOR}=$ adjusted odds ratio; $\mathrm{Cl}=$ confidence interval; $\mathrm{OR}=$ odds ratio (crude); Ref = reference group

* Percentages based on No. of respondents in corresponding subcategories shown in Table I except 'political view'

$\dagger$ Excluded from multivariable analysis because of insignificant differences in univariate analyses

$\neq P<0.01$

$\S P<0.05$

\section{Discussion}

\section{Main findings}

This study provides the first analysis of attitudes towards different policies for deceased organ donation and related determinants. We found that an allocation priority system would significantly motivate respondents to donate their organs, similar to the findings of an Israeli public telephone survey. ${ }^{17}$ The major underlying reason of "fairness or reciprocity" is aligned with the concept of justice, ${ }^{19}$ as organs are a scarce societal resource with a demand that heavily outweighs the supply. The positive effect of a proposed priority incentive on respondents' willingness to donate may be related to possible organ scarcity in the market with the extremely low donation rates in both Israel and Hong Kong. ${ }^{7}$ In addition, the concept of reciprocity might be derived from a moral duty of mutual aid. ${ }^{26}$ Similar to many countries that adopt the priority system, especially Singapore, Hong 
Kong treats moral duty as a legislative foundation. Respondents might have agreed that those who refuse to donate their organs (free-riders) should not receive organs ahead of those who are willing to donate. ${ }^{17}$ Furthermore, respondents , may also have been motivated by priority incentives, providing them with a potential chance to extend their life. This outcome is unsurprising, as it is the key feature of this allocation priority system. ${ }^{16}$

With the increasing demand for organ transplantation, the Hong Kong government has explored the feasibility of an opt-out system. It is worth noting that a proposed opt-out system caused a reduction in the willingness for deceased organ donation, although not to a significant degree. This finding contradicts that suggested by a recent Hong Kong study on kidney donation, ${ }^{20}$ which claimed that the willingness to donate would rise significantly under an opt-out system. This inconsistency may be attributable to an assumption made by that study, that those willing to donate organs under the current opt-in system would remain willing under an opt-out system. Yet, our study found that a large number of respondents who were originally willing to donate changed to being unwilling to stay in the donor pool. The switch was because many initially willing respondents perceived that under an opt-out system, they were "being forced" to donate. Nonetheless, the opt-out system has successfully induced a willingness to donate in many European countries ${ }^{12}$ that also advocate personal liberties. According to a European study, a societal environment was a prerequisite for the government to justify an opt-out system that would limit citizens' liberties. ${ }^{27}$ First, the opt-out system can be imposed only when there are no less restrictive alternatives. Yet, alternatives do exist, such as the allocation priority system. Second, as in the present study, government popularity seems to be another prerequisite condition that was lacking. Distrust of the local government led some respondents to opt out.

Moreover, our study identifies determinants associated with a willingness towards deceased organ donation. Respondents with a lower education level and older age were less likely than others to donate organs under an allocation priority system. These significant factors might arise from a stronger traditional belief among the elderly population of keeping a body intact after death, ${ }^{21}$ as well as a lower awareness of organ donation among those with less education. ${ }^{28}$ The present study also reveals that those who were married were more reluctant than nevermarried people to donate under the opt-out system, because a married person might need a partner's consent before making a decision about donating organs. Echoed by Malaysian and European studies, a trust in government was associated with a higher willingness towards deceased organ donation under the opt-out system. ${ }^{12,22}$

Lower monthly household income was associated with lower willingness to donate organs under both systems. This association may be because those with a higher income are more likely to promote a supportive attitude towards organ donation. ${ }^{29}$ Although the significance of each determinant varied between the opt-out system and the allocation priority system, strengths and directions of the associations were similar across both. More importantly, these significant determinants were also significant under the current opt-in system. ${ }^{30}$ Thus, regardless of the legislative system imposed, determinants associated with willingness to donate appear the same.

\section{Implications of findings \\ Policy-making}

This study provides preliminary evidence of the potential effectiveness of different legislative systems. In particular, the study responds to the recent public controversy over the possible introduction of an opt-out system in Hong Kong, ${ }^{31}$ and may help policymakers anticipate public opposition to such a system. The government should first create a supportive societal environment and gain public trust before its implementation.

At the same time, this study provides evidence to support adding allocation priority to the current opt-in system in Hong Kong. The findings offer policymakers new insight into alternative legislative systems other than the opt-out system. Further evaluation of the priority incentive or other policy instruments is suggested so that policymakers can identify the best alternative.

The design of an administrative procedure to motivate and facilitate registering behaviour should also be considered. Similar to other local studies, ${ }^{6,30}$ this study found that the rate of registration to donate was quite low among those currently willing. The main reasons may be laziness and lack of knowledge about the registration procedure. ${ }^{6}$ Thus, an individual's attitude towards donation is not necessarily aligned with registering behaviour. ${ }^{12,32}$ In other words, combining the opt-in system with allocation priority may not necessarily result in a higher registration and donation rate in practice. Policymakers should consider measures that will simplify the registration procedure. For example, in the United States and the United Kingdom, driving license applicants are invited to register as deceased organ donors. ${ }^{33}$

\section{Education}

Another recommendation stemming from this study is the development of targeted promotion strategies when a new legislative system is introduced. With 
an understanding of determinants of willingness to donate, the Organ Donation Promotion Charter can target those who are less willing to donate. By increasing knowledge and alleviating concerns about procedures involved under the new legislative system, public willingness is expected to increase. ${ }^{12}$ Promotional campaigns should also help build public trust in the government for a smooth implementation of the new system.

\section{Strengths and weaknesses}

The strength of this study is the use of random sampling for respondent recruitment. A randomdigit dialling method was used such that unlisted numbers were also contacted. Each residential telephone number, therefore, had an equal selection probability. With a $95 \%$ residential fixed-line penetration rate, ${ }^{34}$ the sampling frame included most of the Hong Kong general population.

This study has several limitations. There may have been selection bias (selective timing of telephone calls) and self-selection bias (nonresponse after receiving phone calls). Our study is not representative of the general population, as it has fewer respondents who were male, of older age, educated to secondary level, of lower socioeconomic status, and married. In addition, without standardised protocols, information bias may have arisen from recording and classifying responses from the open-ended questions that asked for underlying reasons for change in willingness. Examination of determinants of the willingness to donate was also limited by the small sample size. Subsequent surveys with a larger sample are recommended to investigate socio-demographic variables as well as other possible factors, such as chronic illness requiring an organ transplant in respondents and their relatives or friends.

\section{Conclusion}

This study examined the impact of a proposed opt-in system with organ allocation priority and an opt-out system on willingness towards deceased organ donation among the Hong Kong general population. An allocation priority system could induce willingness to donate. At the same time, the study provides discouraging evidence for the effectiveness of an opt-out system. These findings have implications for policy-making and targeted education. More research is needed to study alternative legislative systems to solve the crisis of organ shortage in Hong Kong.

\section{Acknowledgement}

We thank Ms Yuen-fan Tong for her support and experience in the development of the questionnaire.

\section{Declaration}

The authors have no conflicts of interest to disclose.

\section{References}

1. Matesanz R, Dominguez-Gil B. Strategies to optimize deceased organ donation. Transplant Rev 2007;21:177-88.

2. Wolfe RA, Ashby VB, Milford EL, et al. Comparison of mortality in all patients on dialysis, patients on dialysis awaiting transplantation, and recipients of a first cadaveric transplant. N Engl J Med 1999;341:1725-30.

3. Keown P. Improving quality of life-the new target for transplantation. Transplantation 2001;72(12 Suppl):S67-74.

4. Winkelmayer WC, Weinstein MC, Mittleman MA, Glynn RJ, Pliskin JS. Health economic evaluations: the special case of end-stage renal disease treatment. Med Decis Making 2002;22:417-30.

5. Department of Health, Hong Kong SAR Government. Know more about centralised organ donation register. 2013. Available from: https://www.organdonation.gov.hk/ eng/knowmore.html. Accessed 2 Nov 2016.

6. Hong Kong Ides Centre. A preliminary study on deceased organ donation in Hong Kong. 2015. Available from: http://www.ideascentre.hk/wordpress/wp-content/ uploads/2009/02/Final-Report-for-Organ-Donation-TC. pdf. Accessed 2 Nov 2016.

7. International Registry in Organ Donation and Transplantation. 2015. Available from: http://www.irodat. org/. Accessed 2 Nov 2016.

8. Department of Health, Hong Kong SAR Government. Statistics (milestones of Hong Kong organ transplantation). 2016. Available from: https://www.organdonation.gov.hk/ eng/statistics.html. Accessed 2 Nov 2016.

9. Rodriguez-Arias D, Wright L, Paredes D. Success factors and ethical challenges of the Spanish Model of organ donation. Lancet 2010;376:1109-12.

10. Zúñiga-Fajuri A. Increasing organ donation by presumed consent and allocation priority: Chile. Bull World Health Organ 2015;93:199-202.

11. Johnson EJ, Goldstein D. Medicine. Do defaults save lives? Science 2003;302:1338-9.

12. Mossialos E, Costa-Font J, Rudisill C. Does organ donation legislation affect individuals' willingness to donate their own or their relative's organs? Evidence from European Union survey data. BMC Health Serv Res 2008;8:48.

13. Rithalia A, McDaid C, Suekarran S, Myers L, Sowden A. Impact of presumed consent for organ donation on donation rates: a systematic review. BMJ 2009;338:a3162.

14. Abadie A, Gay S. The impact of presumed consent legislation on cadaveric organ donation: a cross-country study. J Health Econ 2006;25:599-620.

15. Gimbel RW, Strosberg MA, Lehrman SE, Gefenas E, Taft F. Presumed consent and other predictors of cadaveric organ donation in Europe. Prog Transplant 2003;13:17-23.

16. Cronin AJ. Points mean prizes: priority points, preferential status and directed organ donation in Israel. Isr J Health Policy Res 2014;3:8.

17. Siegal G. Making the case for directed organ donation to registered donors in Israel. Isr J Health Policy Res 2014;3:1.

18. Institute of Medicine. Presumed consent. In: Childress FJ, Liverman TC, editors. Organ Donation: Opportunities for Action. Washington, DC: The National Academies Press; 2006: 214 
19. Chandler JA. Priority systems in the allocation of organs for transplant: should we reward those who have previously agreed to donate. Health Law J 2005;13:99-138.

20. Chan TK, Cowling BJ, Tipoe GL. A public opinion survey: is presumed consent the answer to kidney shortage in Hong Kong? BMJ Open 2013;3.pii:e002013.

21. Tumin M, Tafran K, Mutalib MA, et al. Demographic and socioeconomic factors influencing public attitudes toward a presumed consent system for organ donation without and with a priority allocation scheme. Medicine (Baltimore) 2015;94:e1713.

22. Tumin M, Noh A, Jajri I, Chong CS, Manikam R, Abdullah N. Factors that hinder organ donation: religio-cultural or lack of information and trust. Exp Clin Transplant 2013;11:207-10.

23. Troutt MD. Regression, 10k rule of thumb for. In: Kotz $S$, Campbell RB, Balakrishnan N, Vidakovic B, Johnson NL, editors. Encyclopedia of Statistical Sciences. John Wiley \& Sons, Inc; 2004:7098.

24. Census and Statistics Department, Hong Kong SAR Government. By-census results. 2016. Available from: http://www.bycensus2016.gov.hk/en/bc-index.html. Accessed 2 Nov 2016.

25. Lavee J, Brock DW. Prioritizing registered donors in organ allocation: an ethical appraisal of the Israeli organ transplant law. Curr Opin Crit Care 2012;18:707-11.

26. Peters DA. A Unified approach to organ donor recruitment, organ procurement, and distribution. J Law Health 19881989;3:157-87.
27. Verheijde JL, Rady MY, McGregor JL, FriederichMurray C. Enforcement of presumed-consent policy and willingness to donate organs as identified in the European Union Survey: the role of legislation in reinforcing ideology in pluralistic societies. Health Policy 2009;90:26-31.

28. Riyanti S, Hatta M, Norhafizah S, et al. Organ donation by sociodemographic characteristics in Malaysia. Asian Soc Sci 2014;10:265-72.

29. Wong LP. Knowledge, attitudes, practices and behaviors regarding deceased organ donation and transplantation in Malaysia's multi-ethnic society: a baseline study. Clin Transplant 2011;25:E22-31.

30. Surveillance and Epidemiology Branch, Centre for Health Protection, Department of Health, Hong Kong SAR Government. Behavioural risk factor survey (April 2011): main report. 2012. Available from: http://www.chp.gov.hk/ files/pdf/brfs_2011apr_en.pdf. Accessed 2 Nov 2016.

31. Tsang E. Hong Kong to discuss organ donation opt-out scheme following death of girl awaiting double lung transplant. South China Morning Post. 2015 Oct 9.

32. Ugur ZB. Does presumed consent save lives? Evidence from Europe. Health Econ 2015;24:1560-72.

33. Buckley TA. The shortage of solid organs for transplantation in Hong Kong: part of a worldwide problem. Hong Kong Med J 2000;6:399-408.

34. Office of the Communications Authority, Hong Kong SAR Government. Key communications statistics. 2016. Available from: http://www.ofca.gov.hk/en/media_focus/ data_statistics/key_stat/. Accessed 2 Nov 2016. 